\title{
T-Shaped Indan-1,3-dione Derivatives as Promising Electron Donors for Bulk Heterojunction Small Molecule Solar Cell
}

\author{
Tham Adhikari ${ }^{\mathrm{a}}$, Parmeshwar Solanke ${ }^{\mathrm{b}}$, , Dinesh Pathak ${ }^{\mathrm{c} *}$, Tomas Wagner $^{\mathrm{c}}$, Filip Bureš ${ }^{\mathrm{b}}$, \\ Tyler Reed ${ }^{\mathrm{a}}$, Jean-Michel Nunzi ${ }^{\mathrm{a}, \mathrm{d} *}$ \\ ${ }^{a}$ Department of Chemistry, Queens University, Kingston, Ontario, Canada \\ ${ }^{\mathrm{b}}$ Institute of Organic Chemistry and Technology, Faculty of Chemical Technology, University of Pardubice, \\ Studentská 573, Pardubice 53210, Czech Republic \\ ${ }^{c}$ Department of General and Inorganic Chemistry, Faculty of Chemical Technology, University of Pardubice, Studentska 573, \\ Pardubice 532 10, Czech Republic \\ ${ }^{\mathrm{d}}$ Department of Physics, Engineering Physics and Astronomy, Queens University, Kingston, Ontario, Canada \\ dineshpathak80@gmail.com,nunzijm@queensu.ca
}

\begin{abstract}
We report on the photovoltaic performance of novel T-Shaped Indan-1,3-dione derivatives as donors in a solution processed bulk heterojunction solar cells. Small molecule bulk heterojunction solar cells of these molecules with [6,6]-phenyl-C61-butyric acid methyl ester $\left(\mathrm{PC}_{61} \mathrm{BM}\right)$ were fabricated and characterized. The preliminary characterization of these devices yielded a PCE of $0.24 \%$ and $0.33 \%$ for two separate derivatives. These low power conversion efficiencies were attributed to a high surface roughness with a large number of dewetting spots. Doping with $10 \%$ Polystyrene in the Indan-1,3-dione derivatives decreases surface roughness and dewetting spots thereby improving the efficiency of the devices. Efficiency of the devices was found as $0.39 \%$ and $0.51 \%$ for two derivatives after doping with polystyrene. The charge transfer mechanism was studied with photoluminescence quenching. The morphology and packing behavior of molecules were further studied using Atomic Force Microscopy (AFM) and X-ray diffraction (XRD).
\end{abstract}




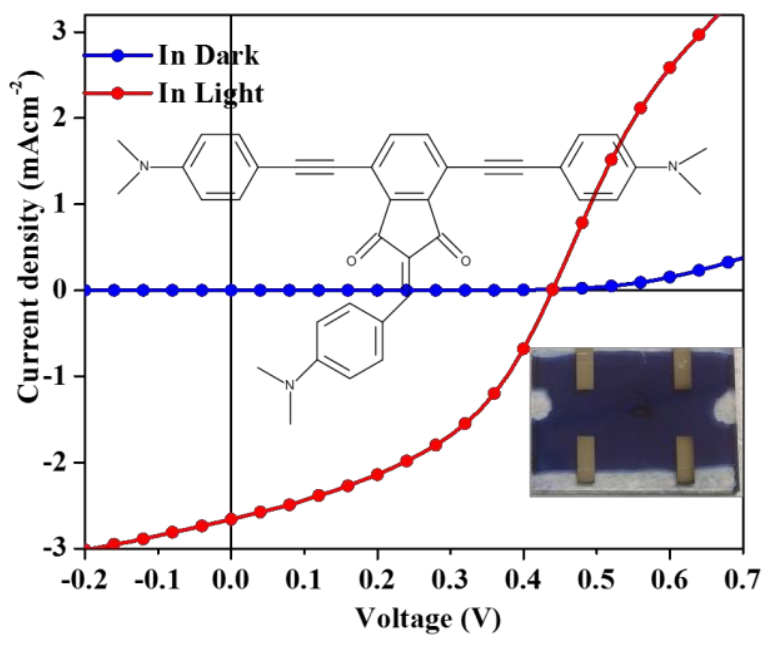

\section{Graphical abstract}

Key Words: Indan-1,3-dione, bulk heterojunction, solar cell, morphology, roughness, XRD, Photoluminescence.

\section{Introduction}

Organic PV cells, a third generation solar cells, have attracted attention worldwide due to their potential for simple, flexible and low cost devices.[1-6] In recent years, great progress has been achieved in the development of solution-processed bulk heterojunction organic PV cells, and the technology has reached the early stages of commercialization.[7] Blending conjugated polymers with high-electron-affinity molecules like fullerene derivatives in bulk-heterojunction promotes a rapid exciton dissociation. [8, 9] Polymer based PV cells have been demonstrated to exhibit power conversion efficiency above $10 \%$.[10, 11] The high efficiency of bulk heterojunctions is due to exciton dissociation at the interface between the electron donor and acceptor materials in the intimately mixed system, followed by efficient charge separation and transport to the electrodes by diffusion of charges in the interpenetrating donor and acceptor network, thereby facilitating efficient charge separation due to large interfacial area.[1, 12-14]. Though high efficiencies were reported in polymer based bulk heterojunction solar cells, batchto-batch variations in solubility, molecular weight, polydispersity and purity for a given polymer yield different photovoltaic performance.[15] Small molecules have distinct advantages as 
compared to polymers such as simple synthesis and purification, well-defined structure, monodispersity, tunability of optical and electronic properties.[15-18] Various strategies were adopted to raise the efficiency of organic photovoltaic cells such as designing low band gap photoactive materials, deepening the highest occupied molecular orbital of the donor to increase the open circuit voltage $\left(\mathrm{V}_{\mathrm{oc}}\right)$, improving morphology and charge transport, and creating ohmic contacts between metal electrodes and photoactive materials for sufficient built-in potential.[16] Most small molecules used in organic photovoltaic are deposited through vacuum thermal deposition, which requires high temperature and are not compatible with flexible solar cells. There are limited small molecules used for solution processed bulk heterojunction solar cells. However, the strong molecular forces between conjugated small molecules can result in the nucleation of molecular crystals in the solution forming incomplete film coverage with high surface roughness.[19] To improve film quality with enhanced efficiency, several efforts were focused on the molecular design. It includes the synthesis of soluble donors with high absorption in the visible to near-infrared region, high charge carrier mobility and high interfacial gap between donor and acceptors.[20] The presence of electron donating and electron withdrawing groups in organic semiconductors leads to an effective internal charge transfer and increase of the conjugation along the molecular scaffold. This results in desired broad absorption and narrow band gap.

Conjugated polymers of which poly(3-hexylthiophene) (P3HT) is an archetype can achieve relatively high power conversion efficiencies, $9.5 \%$ for instance with benzodithiophene moieties.[21] However, they present several drawbacks such as poor batch-to-batch reproducibility at large-scale production, molecular weight, and impurity level.[15, 22] This is why this research along with others focuses on designing solution-processable small-molecule solar cells, ensuring good batch-to-batch reproducibility and relatively easy purification. Solution-processed small-molecule bulk heterojunction solar cells can be produced in large quantities and are amenable to roll-to-roll coating or inkjet printing in order to provide cost effective energy.[23]

In this work, the two Indan-1,3-dione derivatives, shown in Figure 1, were used as electron donors in bulk heterojunction small molecule solar cells. These small molecules show excellent solubility in various organic solvents, excellent optical absorption in the UV-Visible region (350- 
$650 \mathrm{~nm}$ ) and their energy levels match with fullerenes and their derivatives. They are $D-\pi-D$ systems with Indan-1,3-dione as a central acceptor moiety. The synthesis and physico-chemical properties were reported in a previous work.[24] The HOMO, LUMO levels were determined by cyclic voltammetry and reported in this previous work. ${ }^{14}$ Thermal properties showed that they are quite thermally stable. The LUMO levels of these two derivatives lie above the LUMO of PCBM, thus ensuring sufficient driving force for exciton separation.
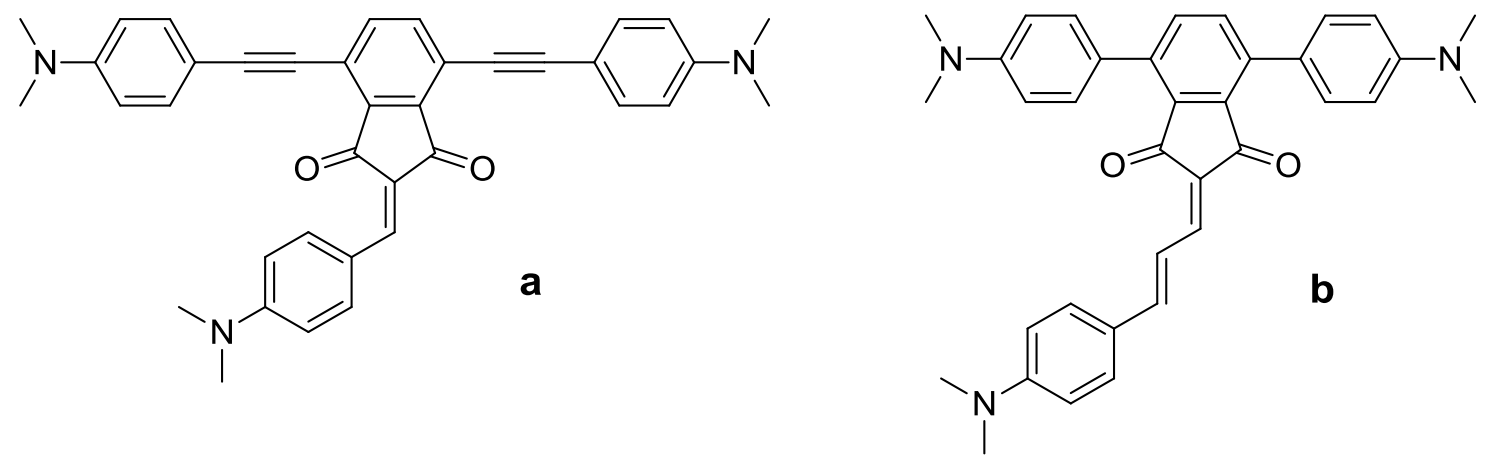

Figure 1 Molecular structures of Indan-1,3-dione derivatives.

\section{Materials \& Methods}

All the solvents and reagents were purchased from commercial sources and used as received without further purification. Indan-1,3-dione derivatives were prepared from commercially available phthalanhydride, its iodination and transformation into 4,7-diiodoindane-1,3-dione intermediate in terms of Claisen condensation. This intermediate underwent Al2O3-catalyzed Knoevenagel condensation with 4-(N,N-dimethylamino)phenyl-substituted aldehydes. The peripheral donors were introduced via two fold Suzuki-Miyaura or Sonogashira cross-coupling reactions with 4-(N,N-Dimethylamino)phenylboronic acid pinacol ester or 4-ethynyl-N,Ndimethylaniline and reported in the previous work. [24] [6,6]-Phenyl C61 butyric acid methyl ester $\left(\mathrm{PC}_{61} \mathrm{BM}\right)$ as electron acceptor was purchased from 1-Material. Poly (3,4ethylenedioxythiophene) polystyrene sulfonate (PEDOT: PSS) used as a hole transport layer was purchased from Ossila. Bathocuproine (BCP, $96 \%$ ) used as hole-blocking layer was purchased from Sigma Aldrich. The patterned Indium tin oxide (ITO) glasses used as substrates were purchased from Luminescence Technology Corporation, which has ITO film thickness about 
$135 \pm 15 \mathrm{~nm}$, and $15 \Omega \mathrm{sq}^{-1}$ sheet resistance. The patterned ITO substrates were cleaned consecutively in an ultrasonic bath with detergent powder, distilled water, acetone and isopropyl alcohol for 10 minutes each and finally dried with air. The substrates were heated at approximately $100{ }^{\circ} \mathrm{C}$ for 5 minutes. The dried substrates were further cleaned in a plasma cleaner for 15 minutes. Poly (3,4-ethylenedioxythiophene) polystyrene sulfonate (PEDOT: PSS) was deposited above cleaned patterned ITO-glass at 4000rpm and annealed at $140{ }^{\circ} \mathrm{C}$ for 20 minutes. The blend solutions of Indan-1,3-dione and PCBM were prepared in chlorobenzene in a fixed ratio (1:1) by weight and stirred for $24 \mathrm{~h}$ at $50{ }^{\circ} \mathrm{C}$. The solution was filtered through a 0.45 $\mu \mathrm{m}$ pore sized poly (tetrafluoroethylene) (PTFE) filter. The active layer was spin-coated at 1000 $\mathrm{rpm}$ and annealed at $110{ }^{\circ} \mathrm{C}$ for 10 minutes. The thickness of the active layer was measured in the range $80-100 \mathrm{~nm}$ with a Sloan Dektak II profilometer. The top and bottom electrodes of the devices were cleaned with a cotton stick soaked with chloroform to make contacts. Finally, 10 $\mathrm{nm} \mathrm{BCP}$ and $100 \mathrm{~nm}$ of Al were deposited with deposition rates of $0.5 \AA / \mathrm{s}$ and $1.0 \AA / \mathrm{s}$, respectively, on all the devices using a physical vapor deposition system (PVD) under high vacuum at a pressure of $1 \times 10^{-6}$ mbar. The active area of the device was $0.06 \mathrm{~cm}^{2}$. The device structure and energy alignment is shown in Figure 2. The LUMO of Indan-1,3-dione derivatives ' $a$ ' and ' $b$ ' are -3.2 and $-3.3 \mathrm{eV}$ respectively. The LUMO of Indan-1,3-dione derivatives is well matched with the LUMO of PCBM, which facilitates the transport of charges towards the electrodes. Under illumination with intensity of $100 \mathrm{mWcm}^{-2}$, the excitons will be generated by absorption of light in the Indan-1,3-dione layers. The charges will be separated at the interface between the Indan-1,3-dione derivative and PCBM junction, and transported towards the oppositely charged electrodes via the BCP electron transport layer and the PEDOT:PSS hole transport layer, resulting in a photovoltaic effect in the device. Current density-voltage (J-V) measurements were carried out with a Keithley 4200-SCS in the dark and under illumination. All photovoltaic parameters of the PV cells were measured at ambient conditions using a Xenon light with an intensity of $100 \mathrm{mWcm}^{-2}$ and calibrated with an AM 1.5 solar simulator.[25] 

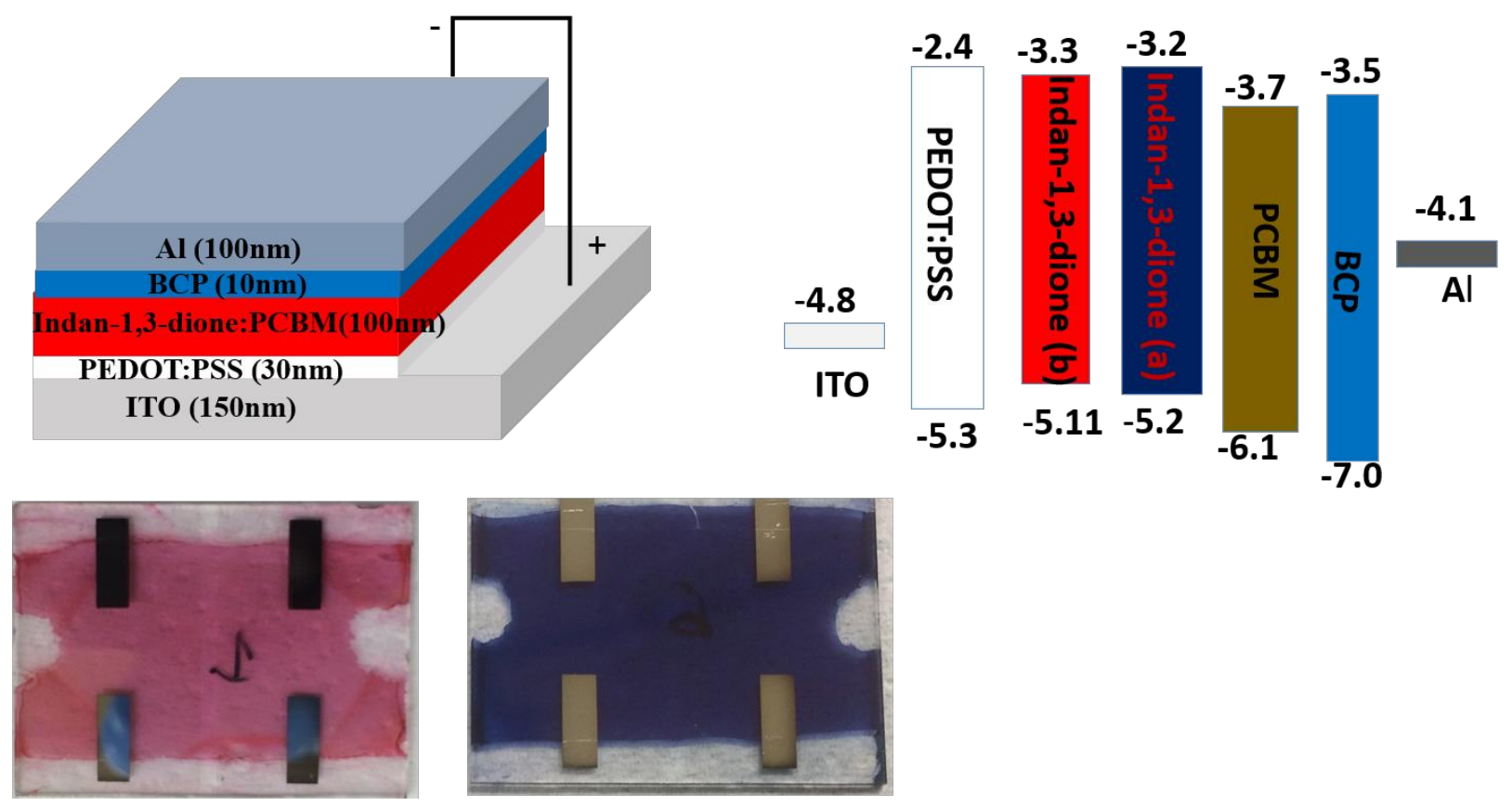

Figure 2 Device structure and Energy level alignment of the device components.

\section{Results and Discussions}

Current-voltage curves in dark and in light are given in Figure 3. The power conversion efficiency (PCE) was calculated from the value of open-circuit voltage $\left(\mathrm{V}_{\mathrm{oc}}\right)$, short-circuit current density ( $\mathrm{J}_{\mathrm{sc}}$ ) and fill factor (FF) as the following equation: $\mathrm{PCE}=\mathrm{P}_{\mathrm{out}} / \mathrm{P}_{\mathrm{in}}=\mathrm{J}_{\mathrm{sc}} \times \mathrm{V}_{\mathrm{oc}} \times \mathrm{FF} / \mathrm{P}_{\text {in }}$ , $\mathrm{P}_{\text {in }}$ represents the Power of incident light $\left(\mathrm{mWcm}^{-2}\right)$. The fill factor was calculated from the values of $\mathrm{V}_{\mathrm{oc}}, \mathrm{J}_{\mathrm{sc}}$, and maximum power $\left(\mathrm{P}_{\max }\right)$ as the following equation: $\mathrm{FF}=\mathrm{P}_{\max } / \mathrm{J}_{\mathrm{sc}} \times \mathrm{V}_{\mathrm{oc}}=$ $\mathrm{J}_{\max } \times \mathrm{V}_{\max } / \mathrm{J}_{\mathrm{sc}} \times \mathrm{V}_{\mathrm{oc}}$, where $\mathrm{J}_{\max }$ and $\mathrm{V}_{\text {max }}$ is the current density and voltage at maximum power respectively. The photovoltaic parameters of devices of Indan-1,3-dione derivatives ' $a$ ' and ' $b$ ' are reported in Table 1. The preliminary results showed that the devices of Indan-1,3-dione ' $a$ ' showed the efficiency $0.24 \%$ with $\mathrm{J}_{\mathrm{sc}}=1.32 \mathrm{mAcm}^{-2}, \mathrm{~V}_{\mathrm{oc}}=0.42 \mathrm{~V}$ and $\mathrm{FF}=0.43$. Similarly, the devices with 1,3-dione derivative ' $\mathrm{b}$ ' showed the efficiency $0.39 \%$ with $\mathrm{Jsc}=2 \mathrm{mAcm}^{-2}, \mathrm{~V}_{\mathrm{oc}}=$ $0.44 \mathrm{~V}$ and $\mathrm{FF}=0.43$. 


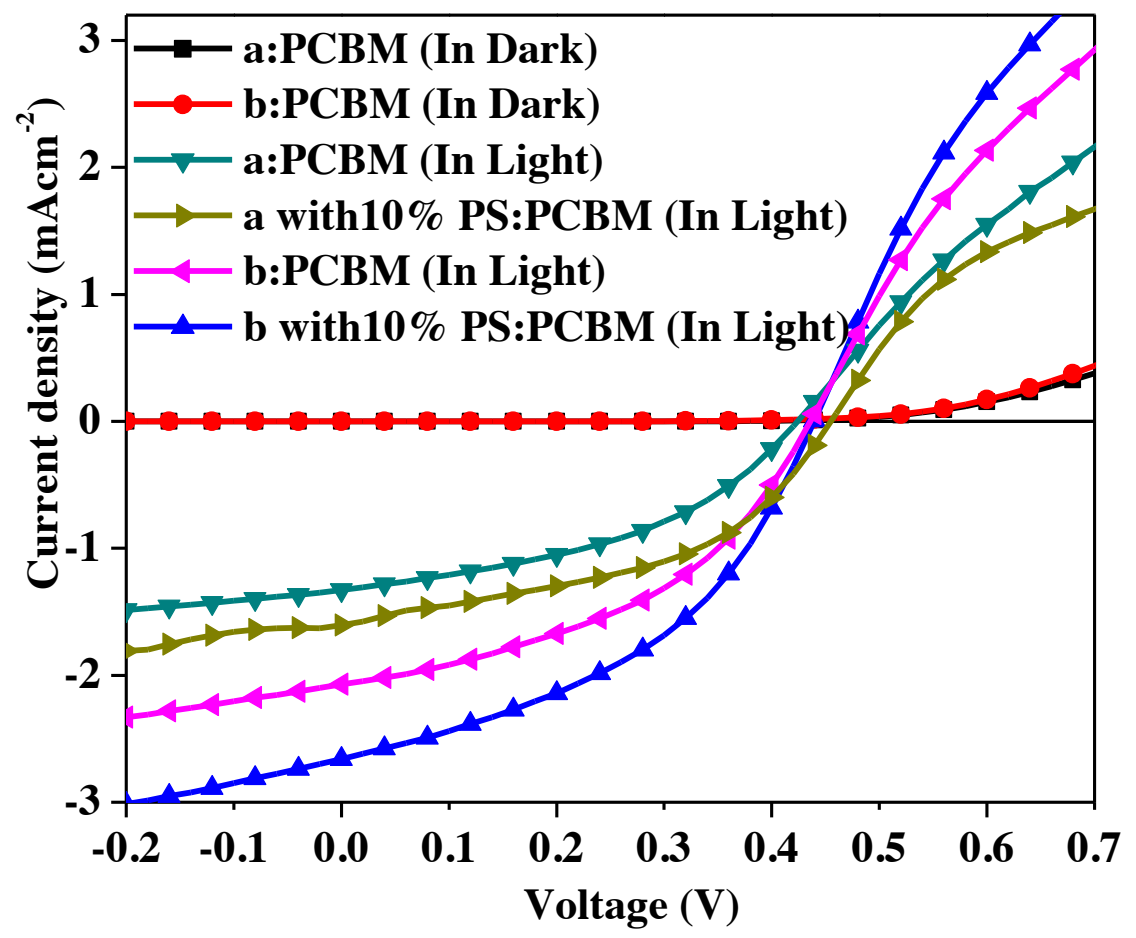

Figure $3 \mathrm{~J}$ vs. V characteristics of ITO/PEDOT:PSS/IN: PCBM /BCP /Al in dark and under 100 $\mathrm{mWcm}^{-2}$ light $\mathrm{w} / \mathrm{o}$ and with doping with polystyrene.

Table 1 Photovoltaic parameters of ITO/PEDOT: PSS /IN: PCBM /BCP /Al bulk-hetero junction devices under $100 \mathrm{mWcm}^{-2}$ light

\begin{tabular}{ccccc}
\hline Device & Jsc $\left(\mathrm{mAcm}^{-2}\right)$ & Voc $(\mathrm{V})$ & FF $(\%)$ & PCE $(\%)$ \\
\hline 'a' & 1.32 & 0.42 & 43.2 & $0.24 \pm 0.01$ \\
'a' with 10 \% PS & 1.60 & 0.46 & 43.6 & $0.33 \pm 0.04$ \\
'b' & 2.0 & 0.44 & 43.4 & $0.39 \pm 0.03$ \\
'b' with 10 \% PS & 2.6 & 0.44 & 43.8 & $0.51 \pm 0.01$ \\
\hline
\end{tabular}


The morphology of nanocomposite of Indan-1,3-dione/PCBM films was characterized using an Ambios multimode atomic force microscope (AFM) in tapping mode with $300 \mathrm{KHz}$ resonant frequency cantilever. AFM topographic images $(10 \mu \mathrm{m} \times 10 \mu \mathrm{m})$ for the blends of PCBM with Indan-1,3-dione derivatives ' $a$ ' and ' $b$ ' are shown in Figure 4. Literature suggests surface roughness for a similar device ranged from $0.907 \mathrm{~nm}-1.49 \mathrm{~nm}$.[26] Our surface roughness is significantly greater $(20-23 \mathrm{~nm})$ than this value and need to be reduced in order to achieve a higher current density and power conversion efficiency. The number of dewetting spots also plays a significant role on the charge density of a film.[23]

The AFM images for the fabricated films shows a very large number of dewetting spots which is indicative of a low charge density and result in a low power conversion efficiency. A literature value shows between 7-17 dewetting spots in a $15 \times 15 \mu \mathrm{m}$ scan.[23] Our 10x10 $\mu \mathrm{m}$ scans show a significantly larger amount of dewetting spots. By visually observing the AFM images under a smaller area $(3 \mu \mathrm{m} \times 3 \mu \mathrm{m})$ in Figure 5, it is possible to determine that there is about one dewetting spot per $\mu \mathrm{m}^{2}$, which may be detrimental to the power conversion efficiency.

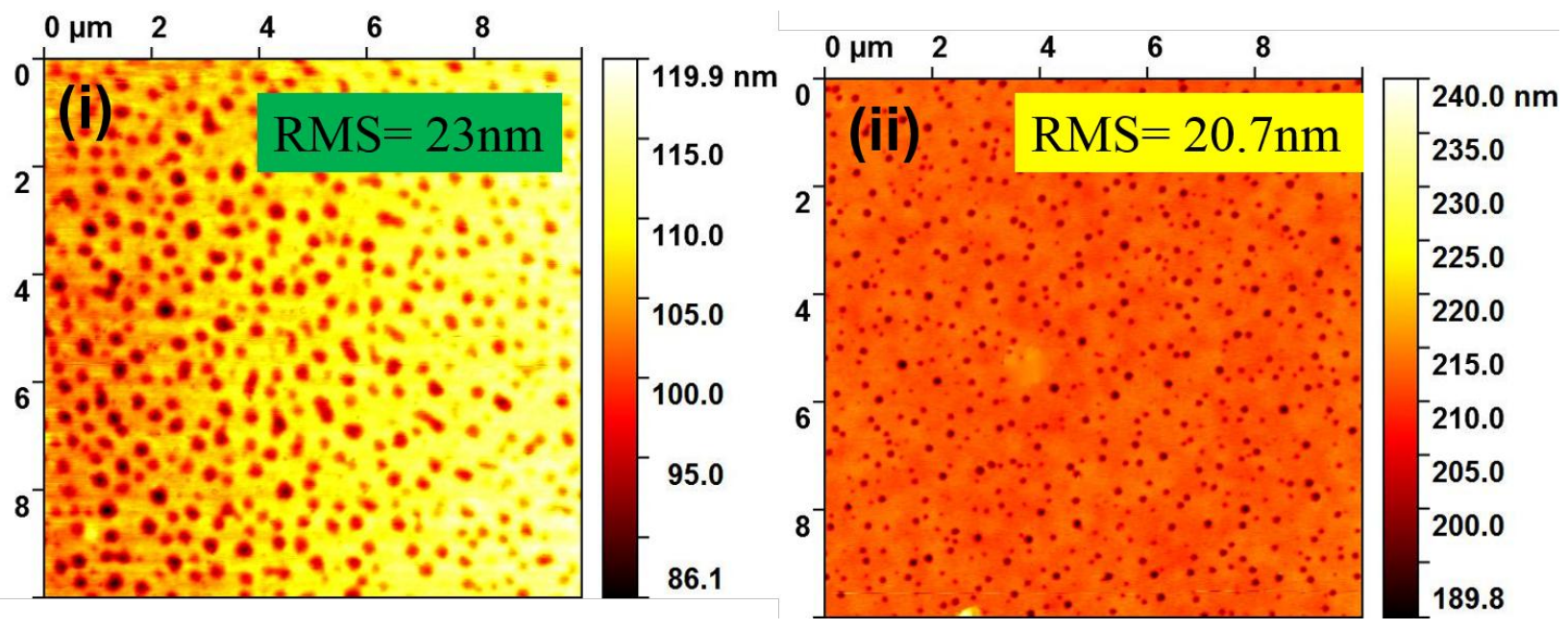

Figure 4 AFM topographic images $(10 \mu \mathrm{m} \times 10 \mu \mathrm{m})$ for the blends of PCBM with Indane-1,3dione derivatives ' $a$ ' and ' $b$ ' w/o doping, (i) 'a':PCBM (ii) 'b':PCBM. 


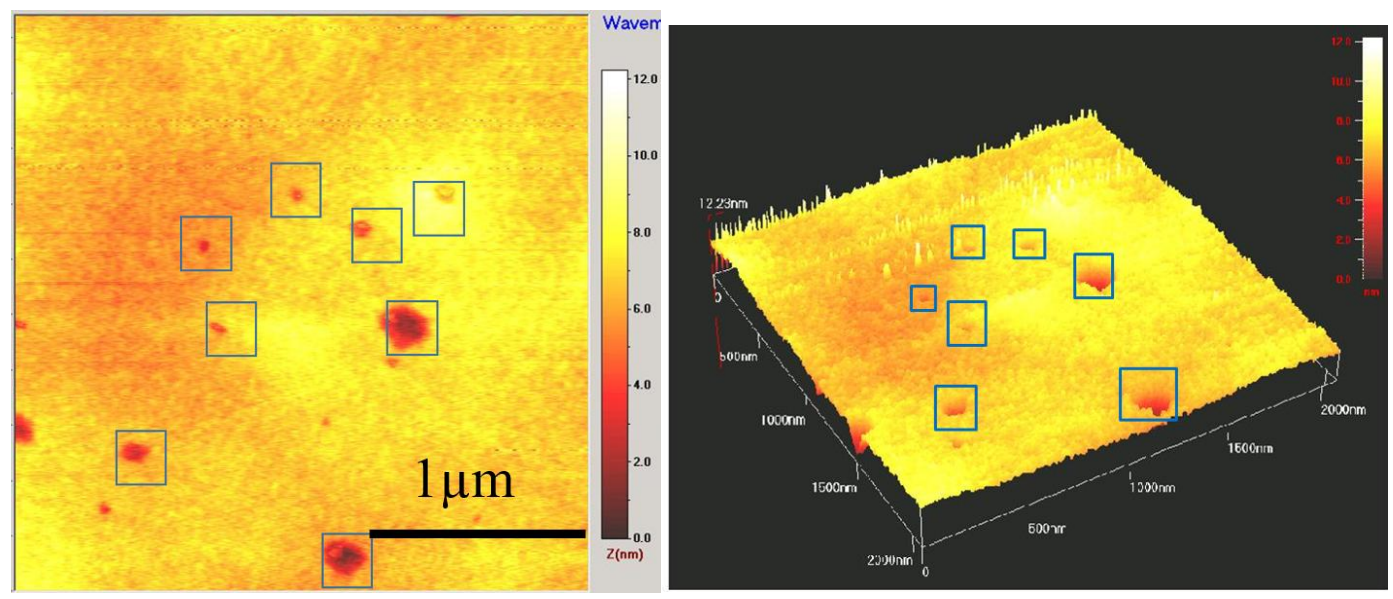

Figure 5 AFM image for blend of Indan-1,3-dione ('a'): PCBM blend $(3 \mu \mathrm{m} \times 3 \mu \mathrm{m})$ in 2D and 3D (Dewetting spots are clearly visible).

A technique found in literature to reduce the number of dewetting spots is to add a small amount of polystyrene to the film.[23] Polystyrene is an inert polymer that has been used to decrease surface roughness and the number of dewetting spots without decreasing device performance. A drastic reduction in the number of dewetting spots upon the addition of $2 \%$ by weight polystyrene and an even greater reduction upon addition of $15 \%$ by weight polystyrene could be achieved.[23] It was shown that up to $50 \%$ of polystyrene could be added without drastically reducing cell performance. It was also being shown that the addition of polystyrene decreases the number of dewetting spots and decreases leakage current. Based on this idea, films were further deposited in the same condition by adding $10 \%$ polystyrene in the Indan-1,3-dione derivatives and morphology was studied by AFM. AFM topographic images $(10 \mu \mathrm{m} \times 10 \mu \mathrm{m})$ for the blends of PCBM with Indan-1,3-dione derivatives ' $a$ ' and ' $b$ ' with Polystyrene are shown in Figure 6. The films are smoother than those without polystyrene, with lower roughness ranging from 1-7 $\mathrm{nm}$ in both derivatives. Dewetting spots almost disappeared by doping with Polystyrene. 

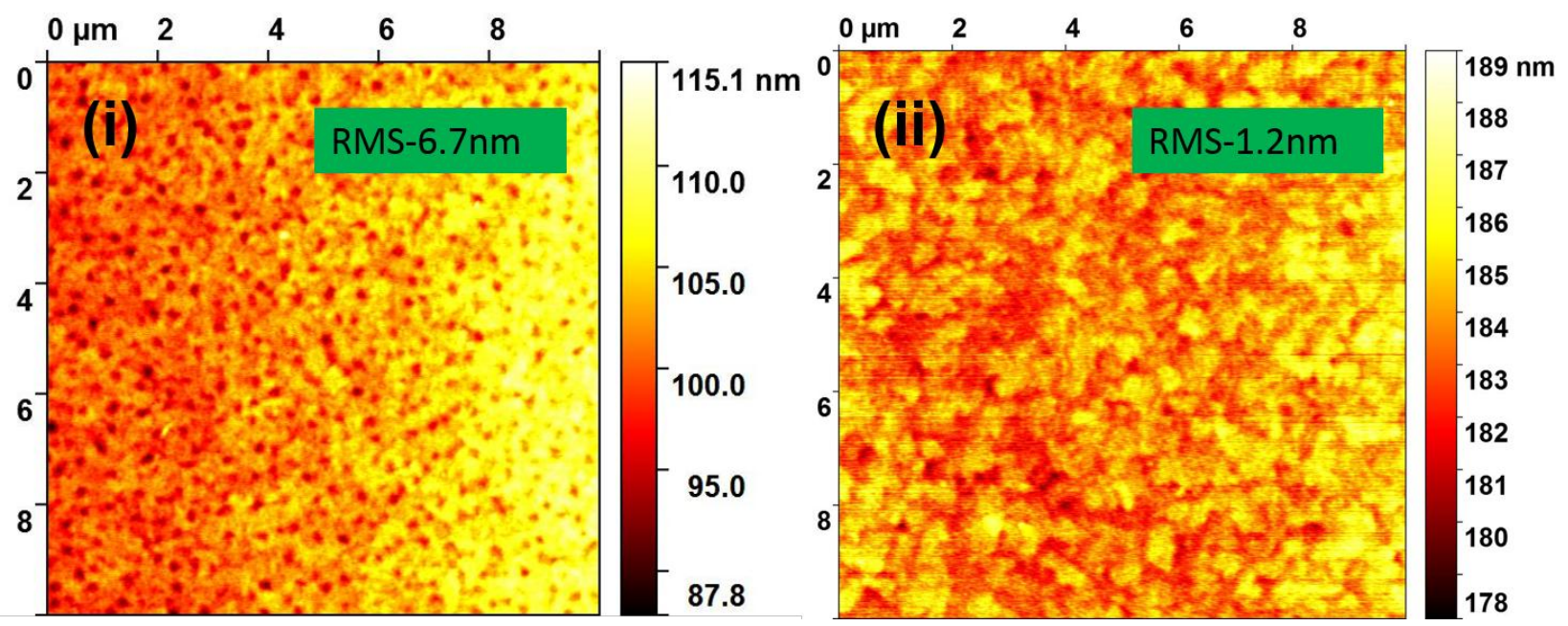

Figure 6 AFM topographic images $(10 \mu \mathrm{m}$ X $10 \mu \mathrm{m})$ for the blends of PCBM with Indan-1,3dione derivatives 'a' and 'b’ with polystyrene doping, (i) ‘a':PCBM (ii) ‘b’:PCBM.

Devices were again fabricated in the same condition as before by doping with $10 \%$ polystyrene in Indan-1,3-dione derivatives. They show an increase in performance by adding $10 \%$ polystyrene. Power conversion efficiency increases $37 \%$, from $0.22 \%$ to $0.33 \%$ for derivative ' $a$ ' with an increase in short-circuit current from $1.32 \mathrm{mAcm}^{-2}$ to $1.60 \mathrm{~mA} \mathrm{~cm}^{-2}$ and $30 \%$ from $0.39 \%$ to $0.51 \%$ for derivative ' $b$ ' with increase in short-circuit current from $2.0 \mathrm{mAcm}^{-2}$ to 2.6 $\mathrm{mA} \mathrm{cm} \mathrm{cm}^{-2}$. J vs. V characteristics of ITO/PEDOT:PSS/IN: PCBM /BCP/Al devices in dark and light after doping is presented in Figure $\mathbf{3}$ and photovoltaic parameters are reported in Table $\mathbf{1}$. Increase in photovoltaic performance after addition of polystyrene is attributable to improvement of charge extraction and collection towards the electrodes.

UV-Visible Spectra were recorded on a HP 8453 Diode array UV-Visible Spectrophotometer. Films of PCBM with Indan-1,3-dione derivatives ' $a$ ' and ' $b$ ' were cast in 1:1 from chlorobenzene solution and annealed at $110{ }^{\circ} \mathrm{C}$ for 10 minutes. The normalized UV-Visible spectra of the pristine Indan-1,3-dione derivatives and their blends with PCBM are shown in Figure 7. It shows a strong absorbance in the UV-Visible range of the spectrum (390-700 nm). The maximum absorbance is around at 510 and $540 \mathrm{~nm}$ for samples ' $\mathrm{a}$ ' and ' $\mathrm{b}$ ' respectively. One additional band appears at 350 and $320 \mathrm{~nm}$ for the pristine samples ' $a$ ' and ' $b$ ' respectively. The blends of samples ' $a$ ' and ' $b$ ' with PCBM show the overlapping absorption with the pristine along with absorption bands at 510 and $540 \mathrm{~nm}$ respectively in the visible region. One additional shoulder also appears at $350 \mathrm{~nm}$ for both blends due to absorption of PCBM. 


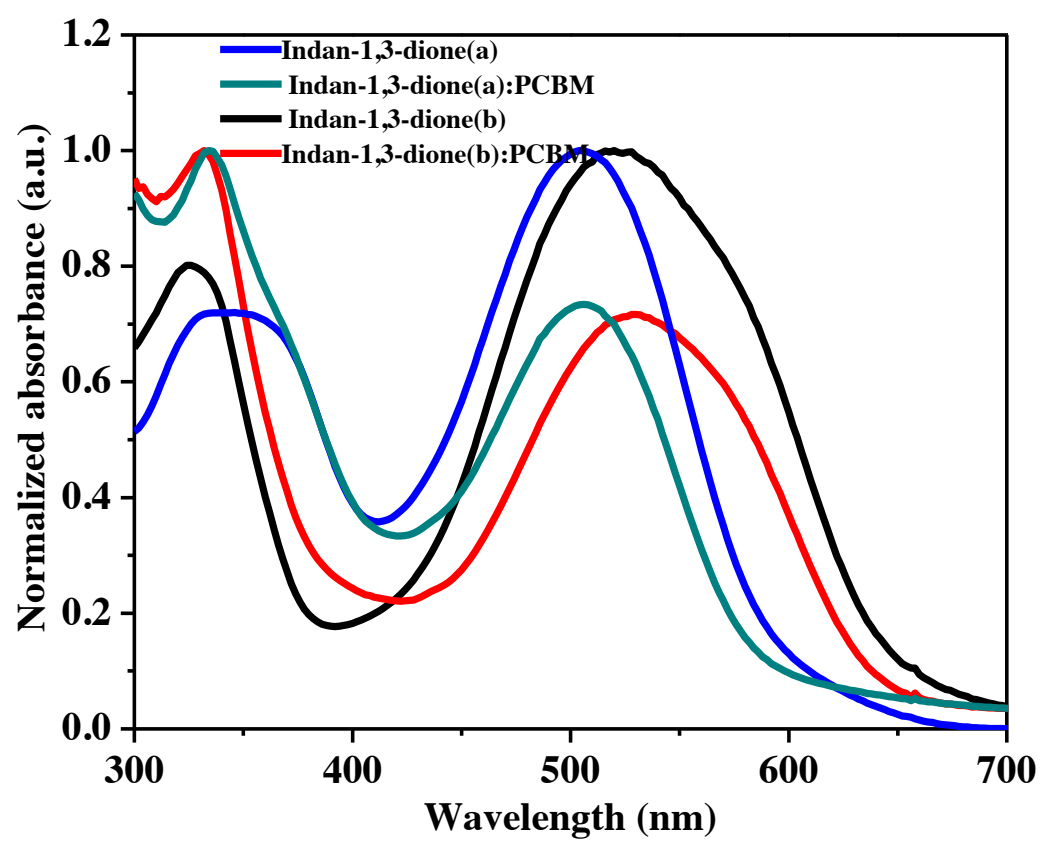

Figure 7 UV-Visible Spectra for Indan-1,3-dione derivatives (a) and (b) and their blends with PCBM.

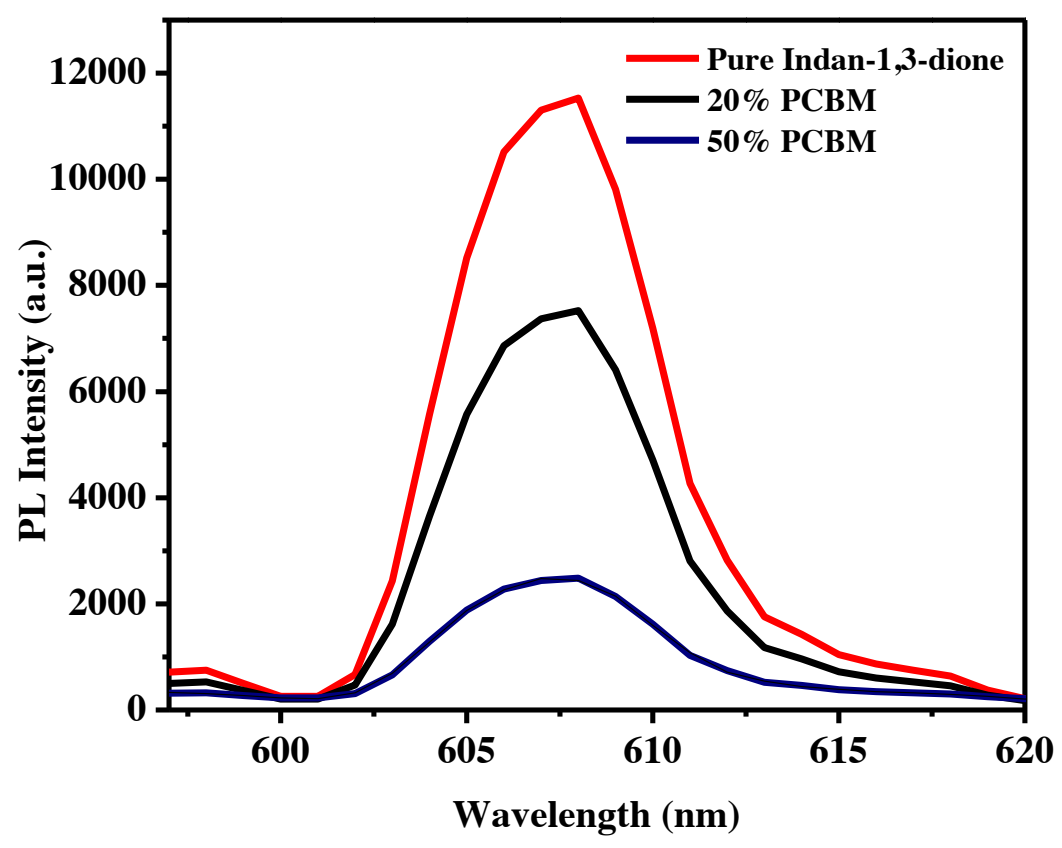

Figure 8 PL spectra for pristine Indan-1,3-dione derivative 'a' and blend with PCBM. 
The charge transfer phenomenon was further studied by photoluminescence quenching. Blend film was prepared by adding $20 \%$ and $50 \%$ of PCBM to the pristine sample from chlorobenzene. PL spectra for pure Indan-1,3-dione derivative (a) and Indan-1, 3-dione derivative: PCBM blended films are shown in Figure 8. PL intensity of the donor is quenched significantly by adding $50 \%$ PCBM in the blended film indicating that excitons created in the donor are close enough to the interface between donor and acceptor. It means charge can transfer from the photo induced excited donor to the acceptor which is good for charge generation in solar cells.

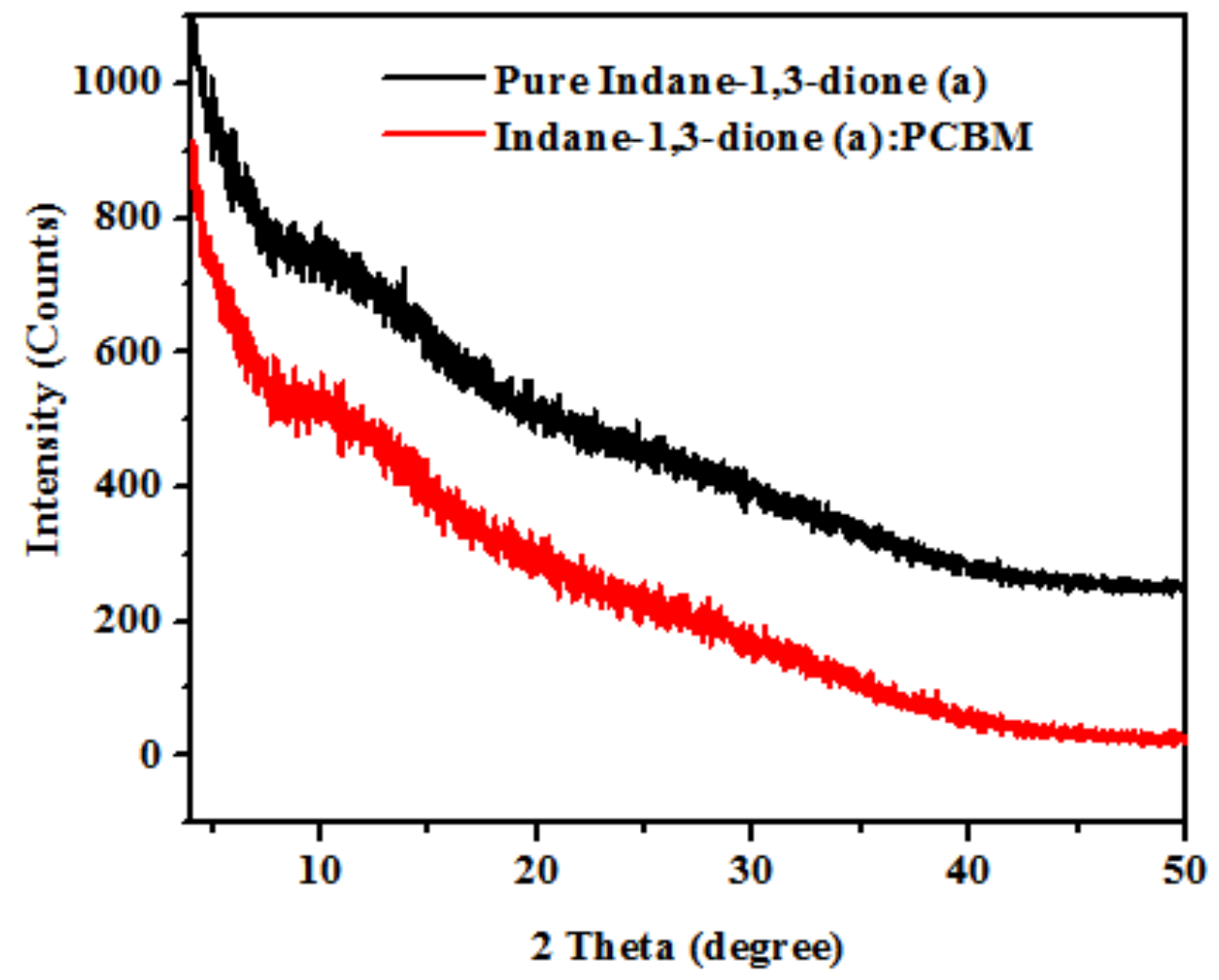

Figure 9 XRD for pristine Indan-1,3-dione derivative ' $\mathrm{a}$ ' and Indan-1,3-dione derivative ' $\mathrm{a}$ ': PCBM blend. The films were annealed at $110{ }^{\circ} \mathrm{C}$ for 10 minutes.

Crystallinity and packing behavior of the pristine and the blends (1:1 ratio) were further studied by X-ray diffraction. X-ray measurements were performed using a Xpert Pro Phillips powder Xray diffractometer with Cobalt $\mathrm{x}$-ray tube $(\Lambda=1.78 \AA)$, Iron filter, graphite crystal 
monochromatic, proportional counter detector, 0.50 divergence slit and $0.25 \mathrm{~mm}$ receiving slit. The XRD results for pristine and the blend after annealing at $110{ }^{\circ} \mathrm{C}$ for 10 minutes is shown in Figure 9. There are no obvious sharp peaks found in the pattern showing the amorphous nature of the Indan-1,3-dione derivatives and PCBM.

\section{Conclusion}

In conclusion, we reported for the first time that T-shaped Indan-1,3-dione based derivatives can be used as donor materials in solution processed small molecule organic solar cells. All devices with Indan-1,3-dione derivatives showed encouraging photovoltaic performances. Photovoltaic parameters were initially found low because of large number of dewetting spots in the thin films as observed by AFM. Addition of a small amount of polystyrene improved thin film morphology with negligible dewetting spots. The presence of a small amount of polystyrene in the Indan-1,3dione derivatives in small molecule bulk heterojunction solar cells improved the overall photovoltaic performance. The power conversion efficiency showed a $37 \%$ increase from 0.22 $\%$ to $0.33 \%$ for derivative 'a' with an increase in short-circuit current from $1.32 \mathrm{mAcm}^{-2}$ to 1.60 $\mathrm{mA} \mathrm{cm}^{-2}$ and a $30 \%$ increase from $0.39 \%$ to $0.51 \%$ for derivative ' $\mathrm{b}$ ' with an increase in shortcircuit current from $2.0 \mathrm{mAcm}^{-2}$ to $2.6 \mathrm{~mA} \mathrm{~cm}^{-2}$. These results permit to increase the database of functional moieties that can work as active materials in organic solar cells.

\section{Acknowledgements}

Research at Queen's was supported by the National Science and Engineering Research Council of Canada (NSERC) Discovery Grants program (RGPIN-2015-05485) and CREATE program (Novel Chiral Materials: An International Effort in Research and Education). Two of the authors (Pathak and Wagner) would like to thank, the Ministry of Education, Youth and Sports of the Czech Republic, Project CZ.1.07/2.3.00/30.0021 "Strengthening of Research and Development Teams at the University of Pardubice". 


\section{References}

[1] L. Dou, J. You, Z. Hong, Z. Xu, G. Li, R.A. Street, Y. Yang, Advanced materials, 25 (2013), pp. 6642-6671.

[2] B. Gholamkhass, N.M. Kiasari, P. Servati, Organic Electronics, 13 (2012), pp. 945-953.

[3] S.K. Hau, H.-L. Yip, A.K.Y. Jen, Polymer Reviews, 50 (2010), pp. 474-510.

[4] D. Pathak, T. Wagner; T. Adhikari, J.-M. Nunzi., Synthetic Metals, 199 (2015), pp. 87-92.

[5] T. Adhikari, Z. Ghoshouni Rahami, J.-M. Nunzi, O. Lebel, Organic Electronics, 34 (2016), pp. 146-156.

[6] R. de Bettignies, Y. Nicolas, P. Blanchard, E. Levillain, J. M. Nunzi, J. Roncali, Advanced Materials 15,22 (2003), p. 1939-1943

[7] C.W. Tang, Applied Physics Letters, 48 (1986), p. 183.

[8] M.C. Scharber, D. Mühlbacher, M. Koppe, P. Denk, C. Waldauf, A.J. Heeger, C.J. Brabec, Advanced Materials, 18 (2006), pp. 789-794.

[9] J.E. Anthony, Chemistry of Materials, 23 (2011), pp. 583-590.

[10] Y. Liu, J. Zhao, Z. Li, C. Mu, W. Ma, H. Hu, K. Jiang, H. Lin, H. Ade, H. Yan, Nature communications, 5 (2014), p. 5293.

[11] S.H. Liao, H.J. Jhuo, P.N. Yeh, Y.S. Cheng, Y.L. Li, Y.H. Lee, S. Sharma, S.A. Chen, Scientific reports, 4 (2014), p. 6813.

[12] J. You, C.C. Chen, L. Dou, S. Murase, H.S. Duan, S.A. Hawks, T. Xu, H.J. Son, L. Yu, G. Li, Y. Yang, Advanced materials, 24 (2012), pp. 5267-5272.

[13] R. Po, J. Roncali, J. Mater. Chem. C, 4 (2016), pp. 3677-3685.

[14] D. Alberga, I. Ciofini, G.F. Mangiatordi, A. Pedone, G. Lattanzi, J. Roncali, C. Adamo, Chemistry of Materials, 29 (2017), pp. 673-681.

[15] Y. Sun, G.C. Welch, W.L. Leong, C.J. Takacs, G.C. Bazan, A.J. Heeger, Nat Mater, 11 (2012), pp. 44-48.

[16] G. Chen, H. Sasabe, T. Igarashi, Z. Hong, J. Kido, J. Mater. Chem. A, 3 (2015), pp. 1451714534.

[17] D. Gebeyehu, B. Maennig, J. Drechsel, K. Leo, M. Pfeiffer, Solar Energy Materials and Solar Cells, 79 (2003), pp. 81-92.

[18] O. Vybornyi, Y. Jiang, F. Baert, D. Demeter, J. Roncali, P. Blanchard, C. Cabanetos, Dyes and Pigments, 115 (2015), pp. 17-22. 
[19] A. Zitzler-Kunkel, M.R. Lenze, N.M. Kronenberg, A.-M. Krause, M. Stolte, K. Meerholz, F. Würthner, Chemistry of Materials, 26 (2014), pp. 4856-4866.

[20] J. Zhou, Y. Zuo, X. Wan, G. Long, Q. Zhang, W. Ni, Y. Liu, Z. Li, G. He, C. Li, B. Kan, M. Li, Y. Chen, Journal of the American Chemical Society, 135 (2013), pp. 8484-8487.

[21] L. Ye, S. Zhang, W. Zhao, H. Yao, J. Hou, Chemistry of Materials, 26 (2014), pp. 36033605 .

[22] G. Wei, R.R. Lunt, K. Sun, S. Wang, M.E. Thompson, S.R. Forrest, Nano letters, 10 (2010), pp. 3555-3559.

[23] E. Destouesse, S. Chambon, S. Courtel, L. Hirsch, G. Wantz, ACS applied materials \& interfaces, 7 (2015), pp. 24663-24669.

[24] P. Solanke, F. Bureš, O. Pytela, M. Klikar, T. Mikysek, L. Mager, A. Barsella, Z.

Růžičková, European Journal of Organic Chemistry, 2015 (2015), pp. 5339-5349.

[25] T. Adhikari, M. Shahiduzzaman, K. Yamamoto, O. Lebel, J.-M. Nunzi, Solar Energy Materials and Solar Cells, 160 (2017), pp. 294-300.

[26] L.-P. Wang, Y. Xia, G.-P. Luo, C.-H. Zhang, Q. Liu, W.-Y. Tan, X.-H. Zhu, H.-B. Wu, J. Peng, Y. Cao, Asian Journal of Organic Chemistry, 4 (2015), pp. 470-476. 